\title{
Neuronal LRP1 Knockout in Adult Mice Leads to Impaired Brain Lipid Metabolism and Progressive, Age-Dependent Synapse Loss and Neurodegeneration
}

\author{
Qiang Liu, ${ }^{1}$ Justin Trotter, ${ }^{6}$ Juan Zhang, ${ }^{1}$ Melinda M. Peters, ${ }^{6}$ Hua Cheng, ${ }^{2}$ Jianxin Bao, ${ }^{3}$ Xianlin Han, ${ }^{2}$ Edwin J. Weeber, ${ }^{6}$ \\ and Guojun $\mathrm{Bu}^{1,4,5}$ \\ Departments of ${ }^{\text {Pediatrics, }}{ }^{2}$ Medicine, ${ }^{3}$ Otolaryngology, and ${ }^{4} \mathrm{Cell}$ Biology and Physiology, ${ }^{5} \mathrm{Hope}$ Center for Neurological Disorders, Washington University \\ School of Medicine, St. Louis, Missouri 63110, and 'Department of Molecular Pharmacology and Physiology, USF Health Byrd Alzheimer's Institute, \\ University of South Florida, Tampa, Florida 33612
}

The vast majority of Alzheimer's disease (AD) cases are late onset with progressive synapse loss and neurodegeneration. Although the amyloid hypothesis has generated great insights into the disease mechanism, several lines of evidence indicate that other risk factors might precondition the brain to amyloid toxicity. Here, we show that the deletion of a major lipoprotein receptor, low-density lipoprotein receptor-related protein 1 (LRP1), in forebrain neurons in mice leads to a global defect in brain lipid metabolism characterized by decreased brain levels of cholesterol, sulfatide, galactosylceramide, and triglyceride. These lipid deficits correlate with progressive, age-dependent dendritic spine degeneration, synapse loss, neuroinflammation, memory loss, and eventual neurodegeneration. We further show that the levels of glutamate receptor subunits NMDA receptor 1 and Glu receptor 1 are selectively reduced in LRP1 forebrain knock-out mice and in LRP1 knockdown neurons, which is partially rescued by restoring neuronal cholesterol. Together, these studies support a critical role for LRP1 in maintaining brain lipid homeostasis and associated synaptic and neuronal integrity, and provide important insights into the pathophysiological mechanisms in AD.

\section{Introduction}

Genetic, biochemical, animal, and human studies have shown that the amyloid- $\beta(\mathrm{A} \beta)$ peptide plays a central role in Alzheimer's disease $(\mathrm{AD})$ pathogenesis. However, increasing evidence indicates that both $\mathrm{A} \beta$-dependent and $\mathrm{A} \beta$-independent mechanisms may contribute to $\mathrm{AD}$. In particular, impaired synaptic and neuronal integrity and functions in the brain may predispose neurons to greater $\mathrm{A} \beta$ toxicity and facilitate disease progression in an age-dependent manner.

Cholesterol is an essential component of neuronal membrane and myelin sheaths, and is crucial for synaptic integrity and neuronal function (Pfrieger, 2003). Reduced synthesis and increased need for cholesterol by neurons in adult brains require active cholesterol transport to these cells to support synaptic functions and repair ( $\mathrm{Bu}, 2009)$. Addition of cholesterol to cultured neurons strongly enhances the number and efficacy of synapses in a manner that depends on apolipoprotein E (apoE) and its receptors (Mauch et al., 2001). Consistent with this finding, depletion

\footnotetext{
Received Aug. 4, 2010; revised 0ct. 11, 2010; accepted 0ct. 20, 2010.

This work was supported by National Institutes of Health (NIH) Grants R01 AG02792405 and P01 AG03012801 to G.B., and R01 AG031675 to X.H.; a Zenith Fellows Award from the Alzheimer's Association; and a research grant from the American Health Assistance Foundation to G.B. We thank the Washington University Viral Vectors Core of the Hope Center for Neurological Disorders (supported by $\mathrm{NIH}$ ) for assisting with the lentivirus production. We also thank Joachim Herz for providing LRP1 loxP mice.

Correspondence should be addressed to Dr. Guojun Bu, Department of Neuroscience, Mayo Clinic, 4500 San Pablo Road, Jacksonville, FL 32224. E-mail: Bu.Guojun@mayo.edu.

DOI:10.1523/JNEUROSCI.4067-10.2010

Copyright $\odot 2010$ the authors $\quad 0270-6474 / 10 / 3017068-11 \$ 15.00 / 0$
}

of cholesterol/sphingolipid leads to instability of surface AMPA receptors, and gradual loss of synapses and dendritic spines (Hering et al., 2003). There is increasing evidence that abnormal cholesterol metabolism in the brain contributes to several neurodegenerative diseases including Niemann-Pick disease type C, Huntington's disease, and AD (Pfrieger, 2003; Valenza et al., 2005). Interestingly, a reduction of brain cholesterol levels is observed in the brains of AD patients (Vance et al., 2006). Although cholesterol homeostasis plays an important role in the pathogenesis of neurodegeneration, the mechanism of its regulation is poorly understood.

Of the three human apoE isoforms (E2, E3, and E4), apoE4 is a strong risk factor for late-onset $\mathrm{AD}$ compared with apoE3 (Mahley, 1988; Bu, 2009). Brain apoE/lipoprotein particles, produced primarily by astrocytes, deliver cholesterol and other lipids to neurons via apoE receptors, which belong to the low-density lipoprotein (LDL) receptor family (Herz and Bock, 2002; Herz and Chen, 2006; $\mathrm{Bu}, 2009)$. The LDL receptor-related protein 1 (LRP1) is highly expressed in neurons of the CNS (Bu et al., 1994). Studies have shown that LRP1 plays critical roles in lipoprotein metabolism, synaptic transmission, and clearance of A $\beta$ peptide (Herz and Bock, 2002; Deane et al., 2004; Lillis et al., 2008; Bu, 2009). Interestingly, LRP1 levels are significantly reduced in AD brains (Kang et al., 2000). The mechanisms by which LRP1 regulates brain lipid metabolism and synaptic integrity and functions remain elusive.

Although apoE and apoE receptors have been implicated in brain lipid metabolism, direct in vivo evidence is lacking. Using a 
genetically altered mouse model, we present evidence demonstrating a strong relationship between brain lipid metabolism and age-dependent dendritic spine and synaptic integrity and functions. We further explored the molecular mechanisms underlying the connection between brain lipid homeostasis and synaptic integrity and found that levels of glutamate receptor subunits NMDA receptor 1 (NMDAR1) and glutamate receptor 1 (GluR1) are selectively lower in the brains of LRP1 knock-out mice. Together, our results reveal a biological function for LRP1 in regulating brain lipid metabolism and synaptic function, providing a novel mouse model to study the $A \beta$-independent neurodegenerative mechanism in $\mathrm{AD}$ and other age-related neurological diseases.

\section{Materials and Methods}

Materials. All tissue culture media and supplements were from Invitrogen. Anti-NMDAR1, anti-NR2A, anti-NR2B, and anti-GluR2/3 were from Millipore Bioscience Research Reagents; anti-GFAP and antiGluR1 were from Abcam; anti-actin was from Sigma and anti-NeuN was from Millipore Bioscience Research Reagents; anti-active caspase-3 and anti-active caspase- 6 were from Cell Signaling Technology; terminal deoxynucleotidyl transferase-mediated biotinylated UTP nick end labeling (TUNEL) staining kit was from Millipore Bioscience Research Reagents. In-house anti-LRP1 and anti-LDL receptor (LDLR) antibodies have been described previously (Liu et al., 2007). Peroxidase-labeled anti-mouse antibody and enhanced illuminance (ECL) system were from GE Healthcare.

Western blot and densitometry analysis. Cells and brain tissues were lysed on ice in lysis buffer (PBS containing 1\% Triton X-100, $1 \mathrm{~mm}$ phenylmethylsulfonyl fluoride, and protease inhibitor mixture from Roche). Protein concentrations were determined using a protein assay kit (Bio-Rad). Equal amounts of protein from each sample were used for SDS-PAGE. The immunoreactive bands were visualized by enhanced chemiluminescence and exposure to film. For densitometric analyses, immunoreactive bands were scanned using a Kodak Digital Science DC120 Zoom camera and quantified using Kodak Digital Science image analysis software.

Immunofluorescence staining. Paraffin sections were blocked with $0.1 \%$ Tween-20, $5 \%$ goat serum in PBS for $30 \mathrm{~min}$ and stained for $2 \mathrm{~h}$ at room temperature with anti-Iba-1, anti-NeuN. Primary antibody was then visualized using Alexa488-labeled goat anti-mouse secondary antibody (Invitrogen). For GFAP staining, frozen sections were blocked and stained with anti-GFAP. Primary antibody was then visualized using Alexa633-labeled goat anti-rabbit secondary antibody (Invitrogen). Cells were counterstained with DAPI (Invitrogen). Fluorescent images were captured with a confocal microscope (Fluoview 500 , Olympus).

TUNEL staining. For the in situ analysis of DNA fragmentation, the TUNEL staining was performed using a commercial kit (Millipore Bioscience Research Reagents). Paraffin sections were prepared from 24month-old $\mathrm{Cre}^{+}$and $\mathrm{Cre}^{-}$mice. The biotin-labeled cleavage sites were visualized by reaction with fluorescein isothiocyanate-conjugated avidin (avidin-FITC).

Stereological analysis. Unbiased stereological cell counts were performed using the optical fractionator method (West et al., 1991) to assess the number of Nissl-positive cells in the cortex and hippocampus. The system consisted of a Nikon Eclipse E800 microscope attached to an Optronics camera with StereoInvestigator software (MicroBrightField). The frozen tissue block was serially sectioned into six series of $50-\mu \mathrm{m}-$ thick sections and stained with $0.25 \%$ thionin (standard Nissl method). For analysis of Nissl-stained sections, a counting frame of $30 \times 30 \mu \mathrm{m}$ and a sampling grid of $150 \times 150 \mu \mathrm{m}$ were used.

Caspase activity. Caspase- 3 and caspase- 6 activities were measured using corresponding Caspase-Glo Assay kits (Promega), as described before (Jiang et al., 2005). Briefly, $50 \mu \mathrm{g}$ of protein extracts of each tissue with equal volume were added to the Caspase-Glo reagents, and caspase activity was measured at 2-3 h. Measurements were performed in triplicate.
Golgi staining and dendritic spine analysis. Golgi staining was performed on 18-month-old $\mathrm{Cre}^{+}$and $\mathrm{Cre}^{-}$mice using the FD Rapid Golgi Stain kit (FD Neuro Technologies), as described previously (Hoe et al., 2009). Briefly, freshly dissected brains were immersed in solution A and $\mathrm{B}$ for 2 weeks at room temperature and then transferred to solution $\mathrm{C}$ for $24 \mathrm{~h}$ at $4^{\circ} \mathrm{C}$. The pyramidal neurons in cortical layers II/III and in the CA1 region of the hippocampus were analyzed. Five neurons were randomly selected per region in each mouse. At least two segments were randomly chosen per neuron from both the apical oblique (AO) and basal shaft (BS) dendrites. Dendritic spines density was measured in a blinded manner.

Primary neuronal culture. Primary mouse cortical neurons were prepared from embryonic day 16 of C57BL/6J mice, as previously described (Hoe et al., 2009). Cultures are grown in neurobasal medium supplemented with B27, $0.5 \mathrm{~mm}$ glutamine, $100 \mathrm{U} / \mathrm{ml}$ penicillin, and $100 \mu \mathrm{g} / \mathrm{ml}$ streptomycin. Neurons were seeded at a density of 200,000 cells per well of 12-well plates or 400,000 cells per well of 6-well plates.

Lentivirus-delivered RNA interference. The lentivirus plasmids carrying LRP1 short hairpin RNA (shRNA) or LDLR shRNA were purchased from Sigma. Lentivirus was produced by the Washington University Hope Center Viral Vectors Core. For control infection, nontarget shRNA was used. Cortical neurons were infected with lentivirus at day 8 in vitro. After 4 or $5 \mathrm{~d}$ of infection, Western blotting or immunofluorescence staining was performed.

Primary astrocyte culture and conditioned medium. Primary cultures of astrocytes were prepared from individual neonatal (1-2-d-old) C57BL/6J mice and cultured in DMEM/Ham's F12 medium containing $10 \%$ FBS, $10 \%$ horse serum, and $1 \mathrm{~mm}$ sodium pyruvate, as described before (Morikawa et al., 2005). Media were conditioned as described previously (Morikawa et al., 2005). Briefly, astrocytes were cultured in serum-free DMEM/F12 media containing 1\% N-2 supplement (Invitrogen), $1 \mathrm{~mm}$ sodium pyruvate, $100 \mathrm{U} / \mathrm{ml}$ penicillin, and $100 \mu \mathrm{g} / \mathrm{ml}$ streptomycin. Three days later, conditioned media were collected and used for neuronal culture.

Cellular cholesterol analyses. Cell lysates were prepared for cholesterol analysis by sonication in PBS with Complete protease inhibitor mixture. The homogenized whole-cell suspension was then subjected to enzymatic analysis for total cholesterol using the Amplex Red Cholesterol Kit (Invitrogen) (Liu et al., 2007).

Animal model, behavioral analyses, and electrophysiology. LRP1 forebrain knock-out mice were generated by breeding the LRP loxP mice (Rohlmann et al., 1998) with $\alpha$ CaMKII-driven Cre recombinase mice (Tsien et al., 1996). Littermates of $\mathrm{Cre}^{+}$and $\mathrm{Cre}^{-}$mice at $13-18$ months of age were used for behavioral analyses. Latency to clasping of the hindlimbs while suspended by the tail was measured for up to $3 \mathrm{~min}$. Rotorod test was performed as previously reported (Qiu et al., 2006), with mice given four trials per day for 2 consecutive days. Latency to remain on the Rotorod was averaged for each trial. The open field test was performed as previously reported (Weeber et al., 2002). Total distance traveled in the open field chamber $(27 \times 27 \mathrm{~cm})$ during 15 min under standard room lighting conditions was assayed. Mouse activity was measured by 16 photoreceptor beams on all sides of the chamber connected to an Activity Monitor program (Med Associates). Zone analysis was performed to determine the time spent in the center of the chamber (designated by an $8 \mathrm{~cm} \times 8 \mathrm{~cm}$ region) compared with the perimeter. For fear conditioning, each mouse was placed in a Plexiglas chamber $(26 \times 22 \times 18 \mathrm{~cm}$; San Diego Instruments) containing a shock grid for $120 \mathrm{~s}$ before introduction of a conditioned stimulus (CS) ( $85 \mathrm{~dB}$ tone) for $30 \mathrm{~s}$. The mouse received an unconditioned stimulus (US) (mild foot shock, $0.5 \mathrm{~mA}$ ) for $2 \mathrm{~s}$ at the end of the conditioned stimulus. After $90 \mathrm{~s}$, another CS-US pairing was presented, and the mouse was returned to its home cage after $2.5 \mathrm{~min}$. Contextual-dependent fear conditioning was measured $24 \mathrm{~h}$ later by introducing the mouse to the same context for $3 \mathrm{~min}$. Next, cued fear conditioning was measured by placing each mouse in a novel environment and allowing it to explore for $3 \mathrm{~min}$ before presentation of the CS ( $85 \mathrm{~dB}$ tone for $3 \mathrm{~min}$ ). Freezing was measured by a CCD camera and defined as a lack of movement for a minimum of $2 \mathrm{~s}$. Long-term potentiation (LTP) was performed as previously reported (Qiu et al., 2006). Briefly, animals were killed, and the hippocampus was quickly dissected 
and recovered in an interface recording chamber. All slices were permitted a minimum $1 \mathrm{~h}$ recovery time before synaptic recording. Standard techniques as reported previously (Weeber et al., 2002) were used to obtain extracellular field recordings and delivery of two titanic train stimulations $(100 \mathrm{~Hz}, 1 \mathrm{~s}$ train at a $20 \mathrm{~s}$ interval). All animal testing procedures were approved by the Institutional Animal Care and Use Committee of Washington University and Vanderbilt University and followed the National Institutes of Health guidelines for the care and use of laboratory animals.

Shotgun lipidomics analysis of brain lipids. Shotgun lipidomics analysis of lipids was performed as described previously (Cheng et al., 2007). Lipids were extracted from each dissected brain tissue by the modified Bligh and Dyer method, as described previously (Cheng et al., 2007). A triple-quadrupole mass spectrometer equipped with a Namomate device, and the Xcalibur system was used to analyze lipids. All tandem mass spectrometry analyses were automatically acquired by a customized sequence operated under Xcalibur software. Internal standards for quantification of individual molecular species of other lipid classes were added to each brain tissue sample.

$A \beta 40$ and $A \beta 42$ determinations. Mouse $\mathrm{A} \beta 40$ and $\mathrm{A} \beta 42$ levels were determined in hippocampal extracts by sandwich ELISA under denaturing conditions ( $0.5 \mathrm{~m}$ guanidine). The capturing antibody was 266 for $\mathrm{A} \beta 40$ and $21 \mathrm{~F} 12$ for $\mathrm{A} \beta 42$, and the detection antibody was biotinylated $2 \mathrm{G} 3$ for $\mathrm{A} \beta 40$ and biotinylated 266 for $\mathrm{A} \beta 42$, as previously described (Zerbinatti et al., 2006). Samples were diluted 10 -fold in PBS containing $0.25 \%$ bovine serum albumin.

Statistical analysis. All quantified data represent an average of at least triplicate samples. All figure data represent the mean \pm SD. Statistical significance was determined by Student's $t$ test, and $p<0.05$ was considered significant (indicated by an asterisk in the figures).

\section{Results}

\section{LRP1 expression is critical for brain lipid homeostasis}

To investigate the roles of LRP1 in the adult brain, we generated conditional LRP1 forebrain knock-out mice by crossing Lrp1 floxP mice with $\alpha$ CaMKII-Cre mice (Liu et al., 2007). Because $\alpha$ CaMKII-Cre is only expressed in neurons of the adult brain (Tsien et al., 1996), the essential function of LRP1 during embryonic development (Herz et al., 1992) is preserved. LRP1 deletion in the forebrain was assessed by comparing LRP1 expression at the protein level between $\mathrm{Cre}^{+}\left(\mathrm{Lrpl}^{f l o x+/+} / \mathrm{Cre}^{+/-}, \mathrm{LRP1}-\mathrm{KO}\right)$ and $\mathrm{Cre}^{-}\left(\mathrm{Lrpp}^{\mathrm{flox+/+}} / \mathrm{Cre}^{-/-}\right.$, WT littermate control) mice at 3, 6, 9, $12,15,18,21$, and 24 months of age. Consistent with $\alpha$ CaMKIIdriven Cre expression in forebrains of adult mice, LRP1 deletion in the cortex of $\mathrm{Cre}^{+}$mice started between 3 and 6 months of age, and gradually reached maximum at $\sim 12$ months of age (supplemental Fig. $1 A, B$, available at www.jneurosci.org as supplemental material). The residual LRP1 expression at older ages likely represents those in glial cells (Moestrup et al., 1992) and along the brain vasculatures (Deane et al., 2004). In addition, inactivation of the $\operatorname{lrp} 1$ gene was mostly specific to the forebrain, as no changes in LRP1 expression were detected in the cerebellum and pituitary (supplemental Fig. 1C, available at www. jneurosci.org as supplemental material).
B

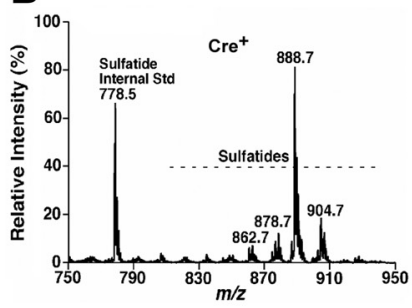

C
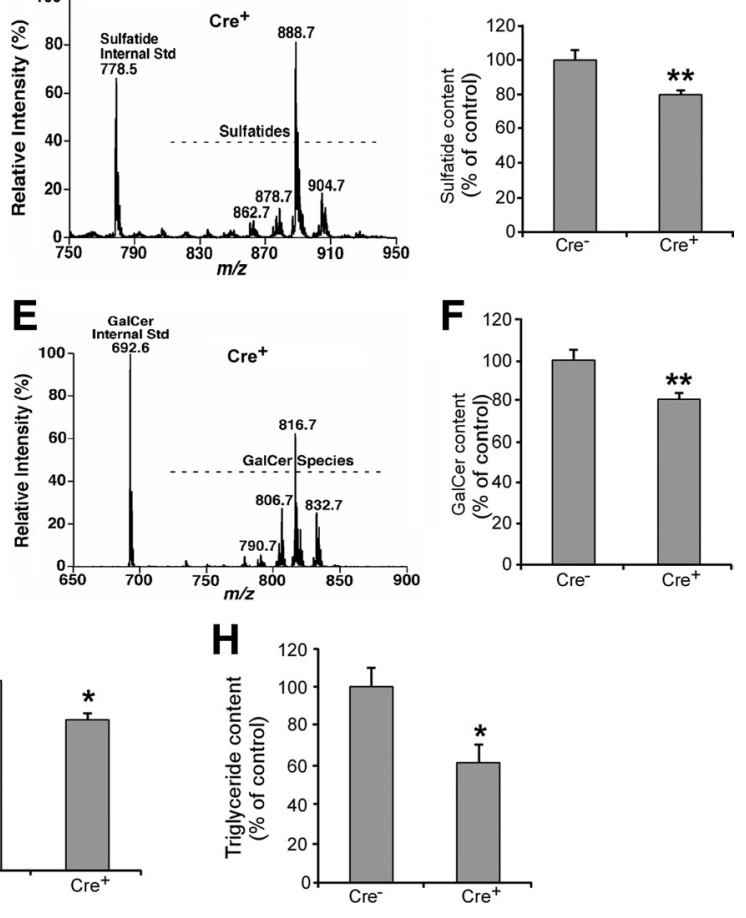

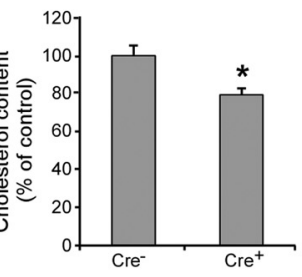

2-month-old Cre ${ }^{+}$and $\mathrm{Cre}^{-}$mice $(n=5)$ were analyzed by shotgun lipidomics. $A-F$, The sulfatides and GalCer contents were reduced in cortical lysates of $\mathrm{Cre}^{+}$mice. $\boldsymbol{A}, \boldsymbol{B}, \boldsymbol{D}, \boldsymbol{E}$, The molecular species of sulfatides $(\boldsymbol{A}, \boldsymbol{B})$ and $\mathrm{GalCer}(\boldsymbol{D}, \boldsymbol{E})$ were indicated in the representative mas mice, normalized against total protein and plotted as a percentage of $\mathrm{Cre}^{-}$controls. The data represent the means \pm SD. of at least four separate animals. ${ }^{*} p<0.01,{ }^{* *} p<0.001$.

LRP1 is a major apoE receptor in the brain (Liu et al., 2007). To understand the role of LRP1 in brain lipid metabolism, shotgun lipidomics (Han and Gross, 2005; Yang et al., 2009) was used to analyze the molecular species of lipid extracts from cortexes of the $\mathrm{Cre}^{+}$and $\mathrm{Cre}^{-}$mice, which were perfused with saline before dissection. We found that there were significantly lower levels of sulfatide (Fig. $1 \mathrm{~A}-\mathrm{C}$ ) and galactosylceramide (GalCer) (Fig. $1 D-F)$ in $\mathrm{Cre}^{+}$mice compared with $\mathrm{Cre}^{-}$littermate controls at 12 months of age. In addition, we found that cholesterol and triglyceride were both significantly decreased in the $\mathrm{Cre}^{+}$mice compared with $\mathrm{Cre}^{-}$mice at 12 months of age (Fig. $1 G, H$ ). To eliminate the possibility that blood might contaminate the lipid samples, we examined the expression of apoB, which is not expressed in the brain. We found that apoB was detected in the brain samples without perfusion, but not with perfusion, suggesting that the lipid samples we analyzed following perfusion were not contaminated by blood (supplemental Fig. $2 \mathrm{~A}$, available at www.jneurosci.org as supplemental material). Together, these results indicate that neuronal LRP1 is critical for brain lipid metabolism and that deletion of this receptor leads to global perturbation of brain lipid homeostasis.

\section{LRP1 expression is important for the integrity of dendritic} spines and synapses

Since lipids play critical roles in neuronal membrane structure, remodeling, and maintenance, we next examined dendritic spine structure from the pyramidal neurons of cortex by Golgi staining. The dendritic spines of the pyramidal neurons in the cortex were 
counted from $\mathrm{AO}$ and $\mathrm{BS}$ dendrites. We found that spine densities of $\mathrm{AO}$ and $\mathrm{BS}$ were significantly lower in $\mathrm{Cre}^{+}$mice compared with $\mathrm{Cre}^{-}$mice at 18 months of age (Fig. $2 A, B$ ), but not at 12 months of age (data not shown). We also analyzed spine density and morphology in pyramidal neurons of the CA1 region in the hippocampus and found that there were similar decreases in spine density in $\mathrm{Cre}^{+}$ mice (Fig. 2C,D) in both $\mathrm{AO}$ and $\mathrm{BS}$ dendrites. These data demonstrate that LRP1 deletion leads to an age-dependent reduction in dendritic spines in pyramidal neurons of the cortex and hippocampus.

The spine abnormalities in $\mathrm{Cre}^{+}$ mice prompted us to analyze whether synaptic density was also affected by neuronal LRP1 deletion. We analyzed the protein levels of synaptophysin and postsynaptic density-95 (PSD-95), which are presynaptic and postsynaptic markers respectively, by Western blotting and found no significant differences in these synaptic markers between $\mathrm{Cre}^{+}$and $\mathrm{Cre}^{-}$ mice at 12 months of age (supplemental Fig. $2 B, C$, available at www.jneurosci.org as supplemental material). However, significant decreases in synaptophysin and PSD-95 were found in $\mathrm{Cre}^{+}$mice at 18 months of age (Fig. 2E,F), suggesting that LRP1 deletion leads to synaptic degeneration in an age-dependent manner.

The pathological changes in $\mathrm{Cre}^{+}$ mice led us to speculate that LRP1 deletion may lead to neuroinflammation in the brain. To test this possibility, we measured reactive astrocyte and microglial activation in the hippocampus of $\mathrm{Cre}^{+}$and $\mathrm{Cre}^{-}$mice. Immunofluorescence staining showed that GFAP-positive astrocytes in the CA1 and dentate gyrus (DG) regions, but not in $\mathrm{CA} 3$ region, were increased in $\mathrm{Cre}^{+}$mice at 18 months of age (Fig. $3 A$ ). Consistent with this finding, LRP1 has been found to be highly expressed in the CA1 and DG regions, but not in the CA3 region (Allen Brain Atlas, http://www.brain-map.org/). Increased glial activation in the hippocampus of $\mathrm{Cre}^{+}$ mice at 18 months of age was confirmed by increased levels of GFAP expression as detected by Western blot analysis (Fig. $3 B, C)$. To assess microglial activation, we performed Iba- 1 staining and found that Iba-1-positive cells were significantly increased in the $C A 1$ and $D G$ regions, but not in the $C A 3$ region, of $\mathrm{Cre}^{+}$mice (Fig. 3D). Increased microglial activation in the hippocampus of $\mathrm{Cre}^{+}$mice at 18 months of age was also confirmed by increased Iba-1 expression levels when analyzed by Western blotting (Fig. 3E,F). To further confirm microglial activation, we measured the expression levels of the proinflammatory cytokines interleukin (IL)- $1 \beta$, tumor necrosis factor (TNF)- $\alpha$, and IL-6 by real-time PCR and found that expression of these cytokines was significantly increased in the hippocampus of $\mathrm{Cre}^{+}$mice (Fig. 3G). These results indicate that neuronal LRP1 deletion leads to neuroinflammation, which could be either a result of spine/synapse degeneration and/or an independent event.
B
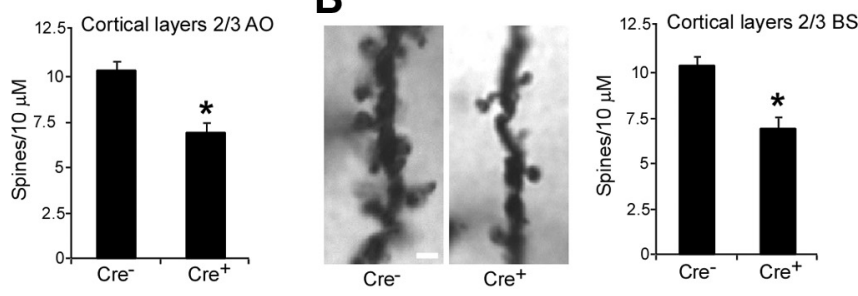

D
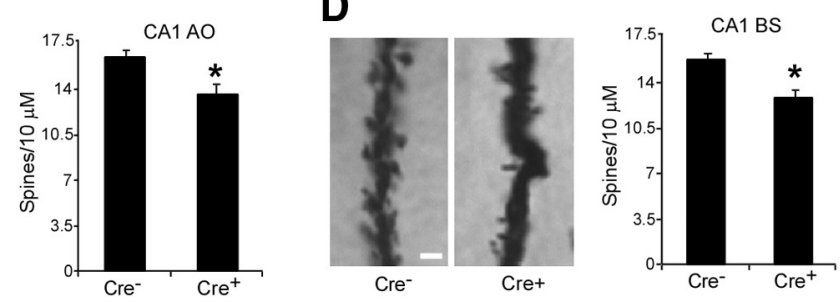

$\mathbf{F}$

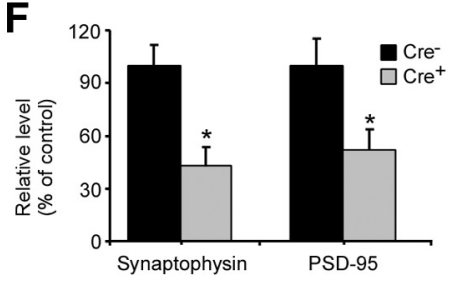

Figure 2. LRP1 deletion leads to age-dependent dendritic spine degeneration and synaptic loss. $\boldsymbol{A}-\boldsymbol{D}$, Representative images of $\mu \mathrm{m}$. The data represent the means \pm SD of at least four separate animals. ${ }^{*} p<0.05$.

\section{Neurobehavioral abnormalities in LRP1 conditional knock-out mice}

The $\mathrm{Cre}^{+}$mice did not exhibit any phenotypes during the first 12 months before LRP1 deletion reached maximum. However, starting at 13 months of age, $\mathrm{Cre}^{+}$mice gradually developed behavioral abnormalities that included motor dysfunction and memory deficits. When suspended by the tail, 13-month-old $\mathrm{Cre}^{-}$mice displayed escape reflexes (hindlimb spread), whereas age-matched $\mathrm{Cre}^{+}$mice promptly clasped their hindlimbs (Fig. $4 A, B)$. Because the rotarod paradigm is a widely used measure of motor coordination in mouse models, we performed this test with 18-month-old $\mathrm{Cre}^{+}$and $\mathrm{Cre}^{-}$mice. We found that the $\mathrm{Cre}^{+}$mice were impaired from the second trial and stayed on the rod for less time than did $\mathrm{Cre}^{-}$mice (Fig. 4C). Interestingly, a previous report by Herz and colleagues (May et al., 2004) demonstrated that pan-neuronal LRP1 deletion leads to severe behavioral and motor abnormalities including hyperactivity, muscle tremor, dystonia, and escape reflexes. In addition, we performed the open field test to analyze general locomotor activity. In comparing the total distance traveled during a 15 min exposure to the chamber, we found that $\mathrm{Cre}^{+}$mice traveled significantly longer distance than $\mathrm{Cre}^{-}$mice (Fig. $4 D$ ). These results indicate that LRP1 deletion in the forebrain neurons leads to hyperactivity in mice.

Because spine degeneration and synapse loss were observed in the hippocampus and frontal cortex in 18-month-old $\mathrm{Cre}^{+}$mice, we next compared memory performance between $\mathrm{Cre}^{+}$mice and $\mathrm{Cre}^{-}$mice at 18 months of age. We first analyzed the freezing 
response of $\mathrm{Cre}^{+}$and $\mathrm{Cre}^{-}$mice to unconditioned stimulus and found that $\mathrm{Cre}^{+}$mice showed a similar freezing response compared with $\mathrm{Cre}^{-}$mice during the last minute of training (Fig. $4 E$ ), suggesting that hyperactivity in $\mathrm{Cre}^{+}$mice does not affect the freezing response. We next evaluated both contextual and cued fear memory in $\mathrm{Cre}^{+}$and Cre ${ }^{-}$mice $24 \mathrm{~h}$ after fear conditioning. $\mathrm{Cre}^{+}$mice exhibited significantly less freezing time than did the Cre ${ }^{-}$mice in both the context test and cue tests (Fig. $4 F, G$ ), suggesting that LRP1 deletion impaired memory at this age. We further measured the long-term potentiation in hippocampal slices of the 18-month-old Cre ${ }^{+}$and Cre ${ }^{-}$mice. Consistent with impaired memory performance in $\mathrm{Cre}^{+}$mice, $\mathrm{Cre}^{+}$mice showed severe LTP deficit compared with $\mathrm{Cre}^{-}$mice (Fig. $4 H$ ). Together, these results demonstrated impaired motor function and memory performance in LRP1 forebrain knock-out mice and indicate a critical role for LRP1 in maintaining neuronal integrity and function in adult brains.

\section{LRP1 expression in aged mice is} important for neuronal survival To gain further insights into neuronal function of LRP1 and to examine whether synapse loss and neuroinflammation lead to eventual neuronal death, TUNEL staining and NeuN staining were performed to analyze potential neuronal death. No significant neurodegeneration was observed in $\mathrm{Cre}^{+}$mice at 18 months of age (data not shown). However, at 24 months of age, $\mathrm{Cre}^{+}$mice showed significant increase in TUNEL-positive cells in the cortex and hippocampus compared with $\mathrm{Cre}^{-}$mice (Fig. 5A,B). Further, we also found at 24 months of age that $\mathrm{Cre}^{+}$mice showed a significant decrease in NeuNpositive cells in the cortex and hippocampus compared with $\mathrm{Cre}^{-}$mice (Fig. $5 C, D)$, suggesting that LRP1 deletion led to age-dependent neurodegeneration. To further confirm this neurodegeneration in $\mathrm{Cre}^{+}$mice at 24 months of age, we performed unbiased stereological analyses of Nissl-stained cells. Consistent with the NeuN staining results, we found that $\mathrm{Cre}^{+}$mice showed significantly fewer neurons in the cortex and CA1 region of hippocampus compared with Cre mice (Fig. 5E). Additionally, we found that the protein levels (Fig. $5 F, G$ ) and the activities (Fig. $5 H, I$ ) of active caspase- 3 and active caspase- 6 were significantly increased in $\mathrm{Cre}^{+}$mice at 24 months of age (Fig. $5 F, I$ ). To examine whether the decreased neuronal survival in $\mathrm{Cre}^{+}$mice was due to potentially increased $\mathrm{A} \beta$ levels, as LRP1 has been implicated in $\mathrm{A} \beta$ clearance $(\mathrm{Bu}, 2009)$, we compared mouse endogenous $A \beta$ levels in $\mathrm{Cre}^{+}$and $\mathrm{Cre}^{-}$mice. We found that the levels of $A \beta 42$ and $A \beta 40$ in the hippocampus were decreased in $\mathrm{Cre}^{+}$mice at 18 months of age (supplemental Fig. 3, available at www.jneurosci.org as supplemental material).
A
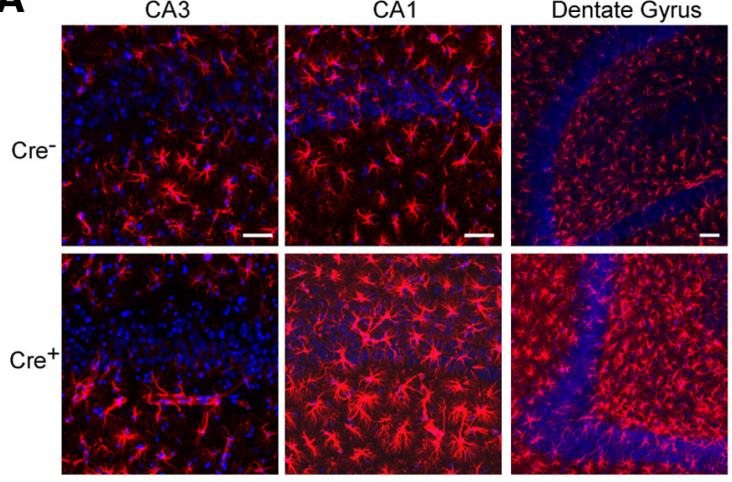

B
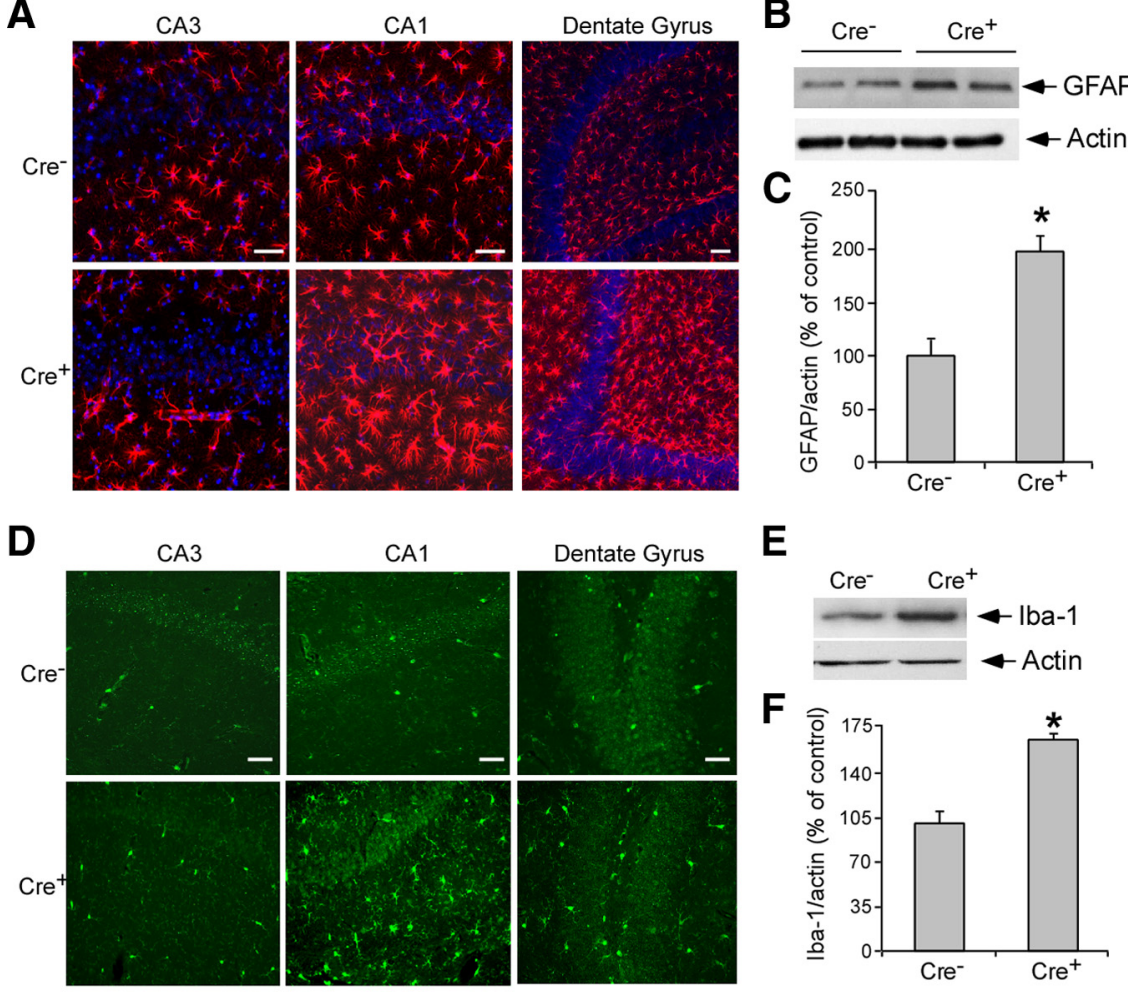

Dentate Gyrus

E
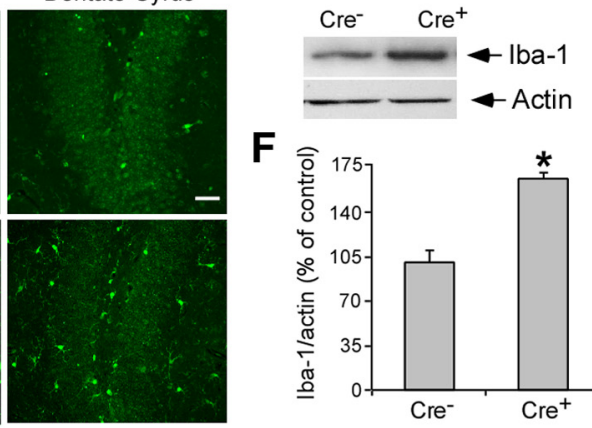

$\mathbf{F}$
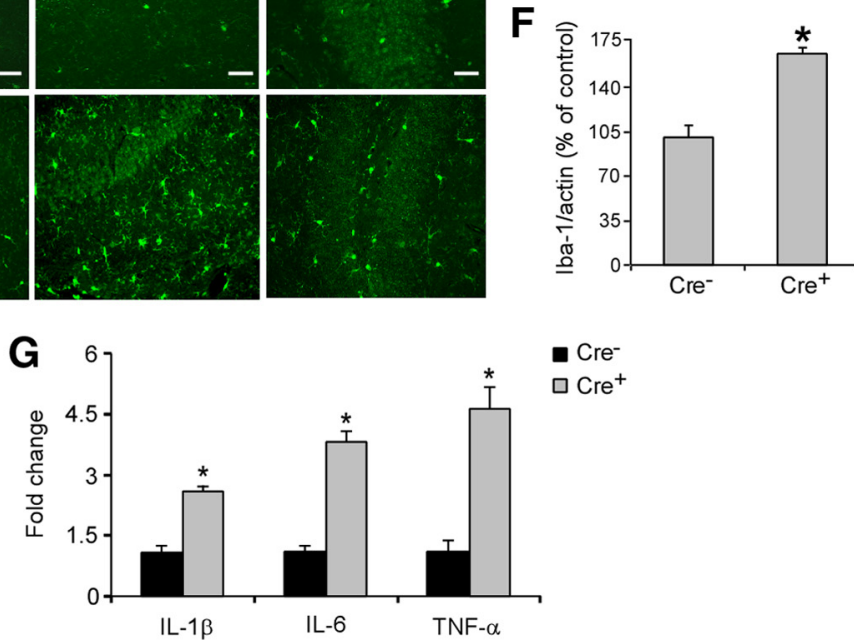

Cre-

$\square \mathrm{Cre}^{+}$

Figure 3. Neuroinflammation in LRP1 forebrain knock-out mice. $\boldsymbol{A}$, Immunofluorescence staining using a GFAP antibody (detected with Alexa 568, red) and nucleic marker DAPI (blue). Shown are representative stainings of the hippocampus of 18month-old Cre ${ }^{+}$and Cre ${ }^{-}$mice. Scale bars, $50 \mu \mathrm{m}$. B. GFAP expression in the hippocampus was evaluated in 18-month-old Cre ${ }^{+}$ I lba-1 antibody (detected with Alexa 488, green). Shown are representative stainings of the hippocampus of 18-month-old ande mice. Scale bars, $25 \mu \mathrm{m}$. $\boldsymbol{E}$, lba-1 expression in the hippocampus was evaluated in 18-month-old Cre and Cre dures $(n=4)$. Note that Ib-1 expression was significantly increased in Cre ${ }^{+}$mice. G, Expression of IL-1 $\beta$, IL- 6 , and TNF- $\alpha$ at the mRNA level in the hippocampus of 18 -month-old Cre ${ }^{+}$and $\mathrm{Cre}^{-}$mice $(n=5)$ was evaluated by real-time PCR. Note that the levels of IL-1 $\beta, \mathrm{IL}-6$, and TNF- $\alpha$ were significantly increased in the $\mathrm{Cre}^{+}$mice compared with $\mathrm{Cre}^{-}$mice. The data represent the means \pm SD of at least four separate animals. ${ }^{*} p<0.01$.

These results are consistent with a function of LRP1 in promoting amyloid precursor protein endocytosis and processing to $\mathrm{A} \beta$ (Cam et al., 2005), and suggest that the decreased neuronal survival in $\mathrm{Cre}^{+}$mice is unlikely due to changes in $\mathrm{A} \beta$ levels. Together, these results demonstrate that LRP1 expression is critical for neuronal survival in the brains of aged mice, likely through an $\mathrm{A} \beta$-independent mechanism.

\section{LRP1 plays a critical role in transporting cholesterol and} maintaining neurite integrity in primary neurons

It has been reported that apoE/cholesterol particles produced by astrocytes promote synapse formation in a manner that depends on the function of apoE receptors (Mauch et al., 2001). Because LRP1 is one of the major apoE receptors in the brain $(\mathrm{Bu}, 2009)$, we directly assessed the roles of LRP1 in maintaining the integrity 
A
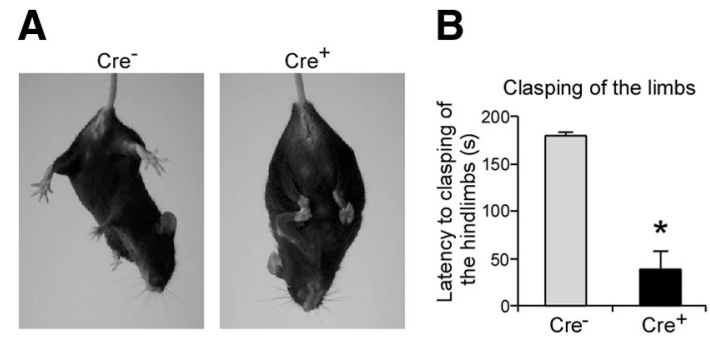

D
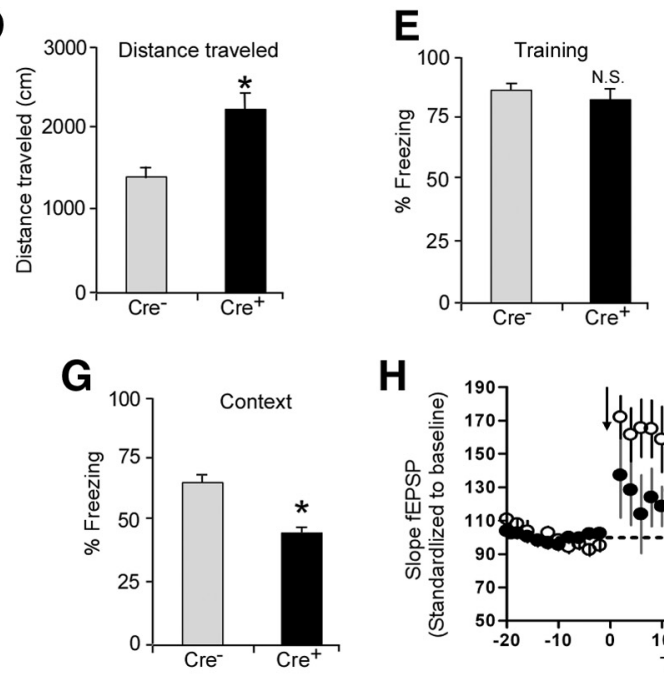

H

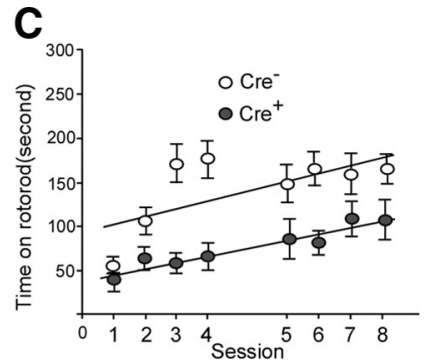

$\mathbf{F}$
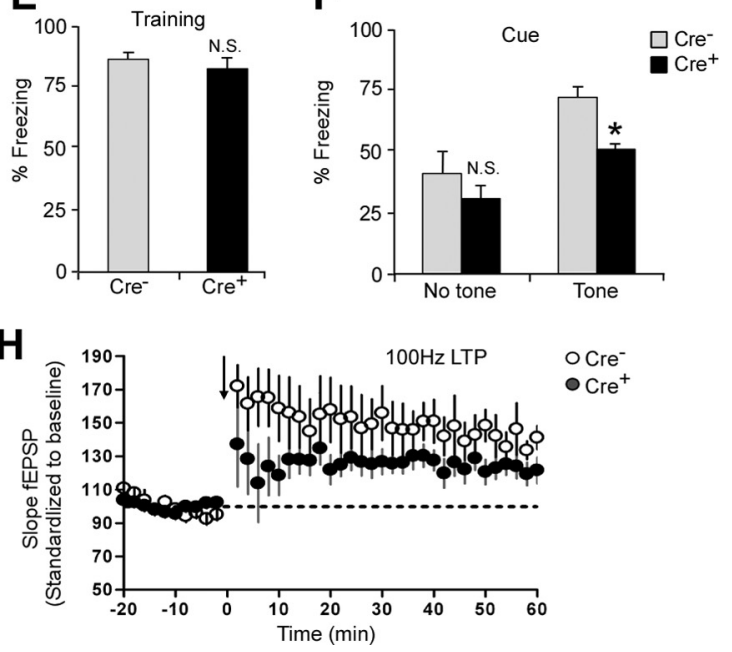

Figure 4. LRP1 deletion leads to neurobehavioral abnormalities. $\boldsymbol{A}, \boldsymbol{B}$, Escape reflexes were tested in 13-month-old Cre ${ }^{+}$and Cre ${ }^{-}$mice $(n=8)$. Deletion of LRP1 decreases the latency to clasping of the hindlimbs. The latency was measured for up to $3 \mathrm{~min}$. C, Rotarod performance is impaired in 18-month-old $\mathrm{Cre}^{+}$mice. Each circle indicates the mean latency to fall on the accelerating rotarod (from 4 to 40 rpm over $5 \mathrm{~min}$ ) ( $n=8$, both genotypes). D, Open field activity was tested in 18-month-old Cre ${ }^{+}$and Cre mice $(n=8)$. Total distance traveled during $15 \mathrm{~min}$ in the open field. $\boldsymbol{E}$, No difference in freezing was seen during the last minute of Fear Conditioning. $\boldsymbol{F}, \mathbf{G}$, Impaired cued and contextual fear memory in 18 -month-old Cre ${ }^{+}$mice $24 \mathrm{~h}$ after training $(n=8$, both genotypes). $\boldsymbol{H}$, LTP deficits in Cre $^{+}$mice. Brain slices were prepared from the hippocampus of 18-month-old Cre ${ }^{+}$and Cre $^{-}$mice. Titanic used to evoke CA1 LTP consisted of two trains of $100 \mathrm{~Hz}$ stimulation for $1 \mathrm{~s}$ with each train separated by a $20 \mathrm{~s}$ interval. The data represent the means \pm SEM. ${ }^{*} p<0.05$.

of spines and synapses in primary neurons cultured in astrocyteconditioned medium containing cholesterol. Lentivirus-mediated delivery of shRNA was used to knock down the expression of LRP1 in primary cortical neurons. LRP1 was efficiently knocked down $4 \mathrm{~d}$ after infection with lentivirus carrying LRP1 shRNA (Fig. 6A,B). To examine the function of LRP1 in neuronal lipid transport, we concentrated conditioned media from astrocytes of wild-type or apoE3 target replacement mice, and incubated them with neurons treated with either control lentivirus or lentivirus carrying LRP1 shRNA. Knockdown of LRP1 expression by shRNA significantly reduced cholesterol content in neurons treated with conditioned medium from the astrocytes of wild-type or apoE3 target replacement mice (Fig. 6C). At day 6 following lentiviral infections, neurites were dramatically decreased and degenerated in neurons infected with LRP1-shRNA but not in controls (Fig. 6D,E). Further, we also found significant decreases in synaptophysin and PSD-95 in neurons infected with LRP1-shRNA but not in controls (Fig. 6F, G). These results suggest that neuronal LRP1 plays a predominant role as an apoE transport receptor in maintaining neurite integrity.

LRP1-mediated cholesterol transport regulates the expression of glutamate receptors NMDAR1 and GluR1

To dissect the mechanism underlying the abnormal synaptic dysfunction and behavioral deficits in $\mathrm{Cre}^{+}$mice, we analyzed the expression of NMDA and AMPA glutamate receptors, which are critical for glutamate-mediated neurotransmission in the brain. Protein levels of NMDAR1 and GluR1 were significantly decreased in 18-month-old $\mathrm{Cre}^{+}$mice compared with age-matched $\mathrm{Cre}^{-}$mice, as determined by immunoblotting (Fig. $7 A, B$ ). This appeared to be an age-dependent effect as no significant changes were detected in 12month-old $\mathrm{Cre}^{+}$mice compared with age-matched $\mathrm{Cre}^{-}$mice (supplemental Fig. $4 A, B$, available at www.jneurosci.org as supplemental material). To investigate whether changes in the expression of NMDAR1 and GluR1 occurred at transcriptional level, we compared NMDAR1 and GluR1 mRNA levels by real-time PCR. As shown in supplemental Figure 4C (available at www.jneurosci.org as supplemental material), NMDAR1 and GluR1 mRNA levels were not significantly altered in 18-month-old Cre ${ }^{+}$mice when compared with age-matched $\mathrm{Cre}^{-}$mice. As controls, we also compared the expression of neurotrophin receptors TrkA and p75 in 18-month-old $\mathrm{Cre}^{+}$and Cre ${ }^{-}$ mice by Western blotting and found no significant differences in the expression of these receptors (supplemental Fig. 4D,E, available at www.jneurosci.org as supplemental material). To understand whether impaired lipid metabolism in LRP1 forebrain knock-out mice was responsible for decreased expression of NMDAR1 and GluR1, we investigated the role of LRP1 and cholesterol in regulating the expression of these glutamate receptors in primary neurons. Consistent with the in vivo data, we found that the expression of NMDAR1 and GluR1 was significantly reduced in LRP1 knocked down neurons (Fig. 7C,D). When a cholesterol $(10 \mu \mathrm{g} / \mathrm{ml})$ supplement was administered to LRP1-knockdown neurons, expression of NMDAR1, but not GluR1, was restored (Fig. $7 E, F$ ). Further, when primary neurons were treated with cholesterol synthesis inhibitor simvastatin, expression level of NMDAR1, but not LRP1, was significantly decreased (supplemental Fig. 5A, $B$, available at www.jneurosci.org as supplemental material). These results suggest that LRP1 likely regulates NMDAR1 level at least partially by modulating cholesterol homeostasis.

\section{Discussion}

Although apoE4 and impaired lipid metabolism have been implicated in the pathogenesis of $\mathrm{AD}$, the underlying molecular mechanisms and pathways are not clear. In this study, we showed that deletion of the apoE/lipoprotein receptor LRP1 from forebrain neurons of adult mice leads to global impairment in brain lipid metabolism. More interestingly, the reduced brain lipid levels correlated with progressive, age-dependent degeneration of dendritic spines and synapses, impaired neurobehaviors, and eventual neurodegeneration. We further showed that reduced levels of selective glutamate receptors may contribute to impaired synaptic functions in LRP1-KO mice. Together, our work provides 
A

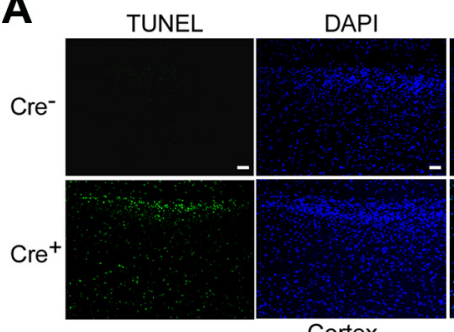

Cortex

C

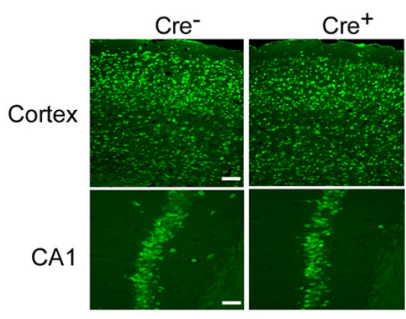

F

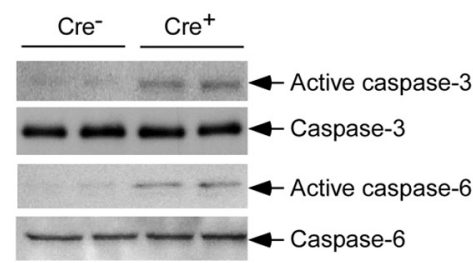

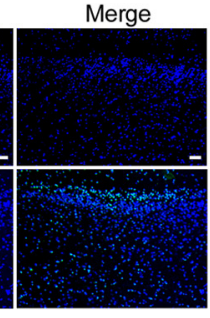

D

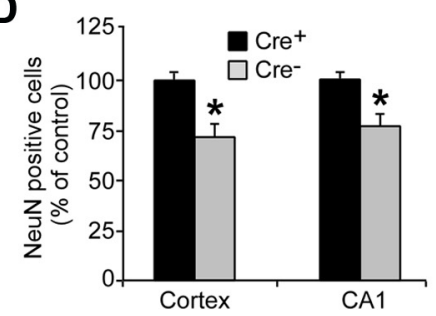

B

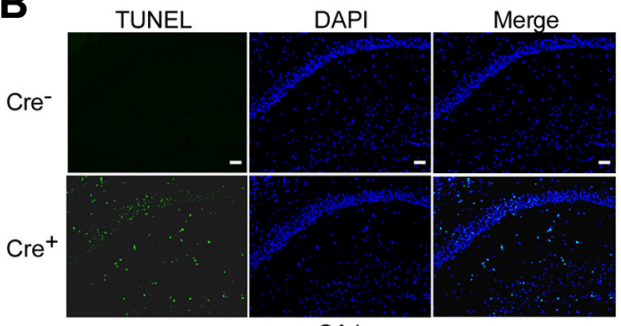

CA1

E
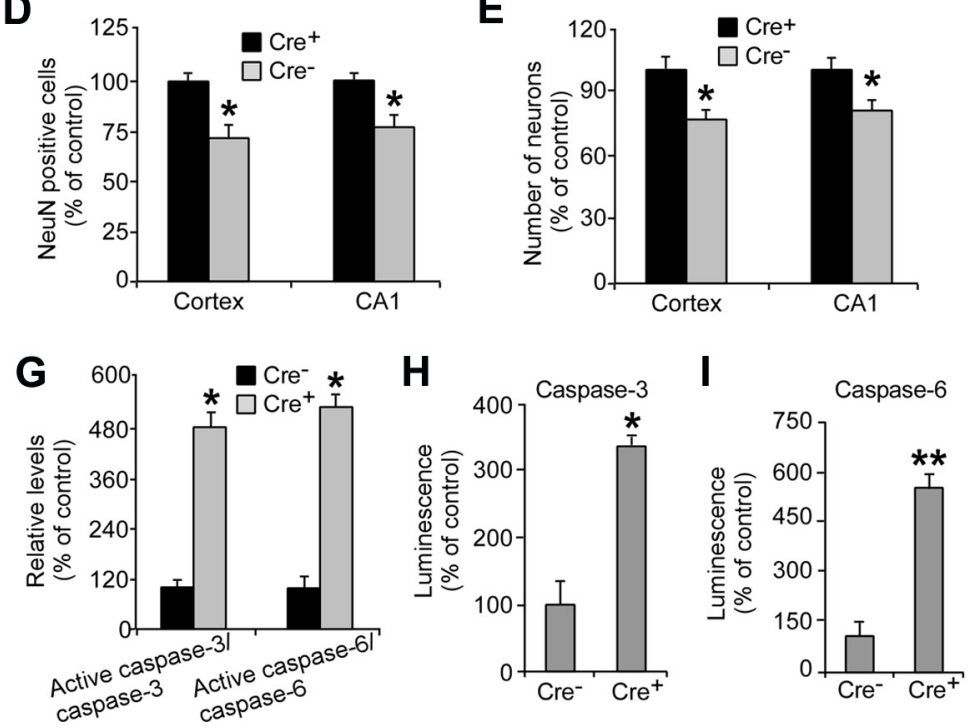

Figure 5. LRP1 deletion leads to age-dependent neurodegeneration. $A, B$, TUNEL staining was performed in the cortex and hippocampal CA1 regions of $24-$ month-old $C r e{ }^{+}$and $C r e{ }^{-}$mice $(n=$ 5). Representative images of TUNEL staining are shown (detected with FITC, green and nucleic marker DAPI, blue). Scale bars, $25 \mu \mathrm{m}$. $\boldsymbol{C}, \boldsymbol{D}$, NeuN staining was performed in the cortex and hippocampal CA1 region of 24-month-old $\mathrm{Cre}^{+}$and $\mathrm{Cre}^{-}$mice $(n=5)$. Representative images of NeuN staining are shown (detected with Alexa 488, green). Scale bars, $25 \mu \mathrm{m}$. $\boldsymbol{E}$, Stereological analysis was performed in the cortex and hippocampal CA1 region of 24-month-old $\mathrm{Cre}^{+}$and $\mathrm{Cre}^{-}$mice $(n=5)$. $F$, Levels of active-caspase-3, active-caspase-6, total caspase-3, and total caspase- 6 in the cortex were evaluated in 24-month-old $\mathrm{Cre}^{+}$and $\mathrm{Cre}^{-}$mice by Western blotting. $\mathbf{G}$, Densitometric quantification of active caspase versus total caspase was performed as described in Experimental Procedures $(n=4)$. Note that active-caspase-3 and active-caspase-6 levels were significantly increased in $\mathrm{Cre}^{+}$mice. $\boldsymbol{H}, \boldsymbol{I}$, Caspase- 3 and caspase- 6 activities were measured using a luciferase-based assay system (Promega), normalized against total protein, and plotted as a percentage of Cre ${ }^{-}$controls $(n=4)$. Scale bars, $100 \mu \mathrm{m}$. The data represent the means \pm SD of at least four separate animals. ${ }^{*} p<0.05,{ }^{* *} p<0.01$.

strong evidence that brain lipid metabolism is critical for maintenance of the integrity and functions of neuronal synapses, and establishes a novel mouse model in which impaired brain lipid metabolism leads to age-dependent dendritic spine, synapse, and neurodegeneration.

LRP1 is a major neuronal receptor for brain apoE/lipoprotein (Liu et al., 2007; Bu, 2009). It is highly expressed in neurons, and its rapid endocytosis ( $\mathrm{Li}$ et al., 2000) and efficient recycling (van Kerkhof et al., 2005) likely contribute to its role as a key lipid transporter for neurons. Cholesterol is an essential component of membranes and myelin sheaths, and is crucial for synaptic integrity and neuronal function. Because LRP1 levels are significantly reduced in $\mathrm{AD}$ brains, which correlate with increased $\mathrm{AD}$ susceptibility (Kang et al., 2000), it is tempting to speculate that decreased LRP1 levels in AD could be directly responsible for cholesterol loss and related synaptic dysfunction independently of $A \beta$ accumulation. GalCer and its sulfated derivative, sulfatide, are major lipid components in the myelin sheaths (Ishizuka, 1997; Merrill et al., 1997). Deletion of ceramide galactosyltransferase (CGT), which is required for the synthesis of GalCer and sulfatide, leads to dysmyelinosis and death of CGT knock-out mice (Bosio et al., 1996; Coetzee et al., 1996). It has been found that a marked decrease of sulfatide levels in the brain is associated with AD pathology (Han et al., 2002), and that sulfatides are specifically associated with apoE-containing high-density lipoprotein-like particles (Han et al., 2003). In the adult brain, apoE/lipoprotein particles are synthesized and secreted primarily by astrocytes (Pfrieger, 2003; Puglielli et al., 2003). ApoE particles then acquire sulfatides from the myelin sheaths likely through a "kiss-and-run" mechanism (Han, 2007). These sulfatidecontaining apoE particles can be internalized by neurons via lipoprotein receptors and then hydrolyzed in neuronal lysosomes, allowing intracellular release of free cholesterol, sulfatide, and other lipids (Pfrieger, 2003; Han, 2007). A function for LRP1 in brain lipid metabolism has been postulated (Han, 2007), but direct biological evidence had been lacking. Our findings provide direct evidence that deletion of LRP1 significantly alters the brain levels of sulfatide, GalCer, and cholesterol, all of which are critical for the integrity of neuronal membranes, dendritic spines, and synapses. Interestingly, triglyceride was also decreased in the LRP1 knock-out mice. Previous studies have demonstrated that apoE is associated with triglyceride metabolism in the nervous system (Cheng et al., 2007). It has been reported that triglycerides account for $<1 \%$ of the total lipids in mouse brain (Su and Sun, 1978). However, the exact function of triglyceride in the brain is not clear. It is generally accepted that brain energy metabolism was solely dependent on the glucose. However, increasing evidence shows that brain also used other energy resources, such as 

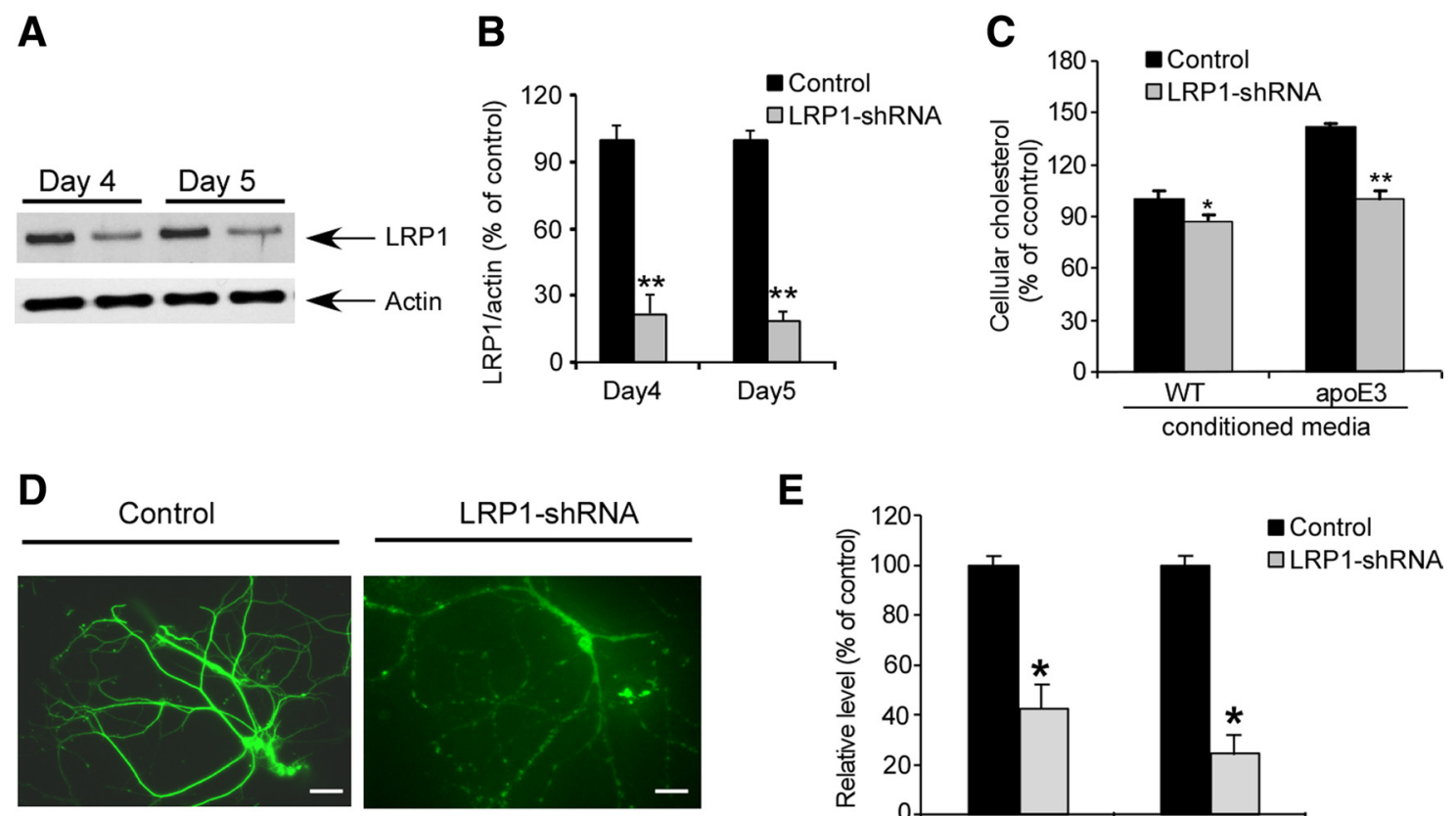

E

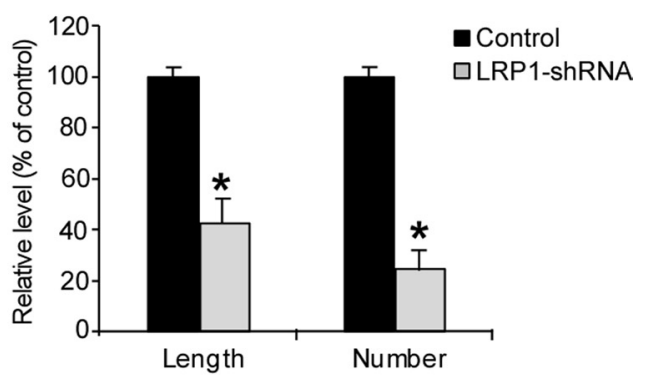

$\mathbf{F}$

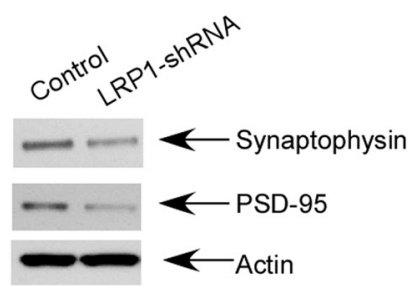

G

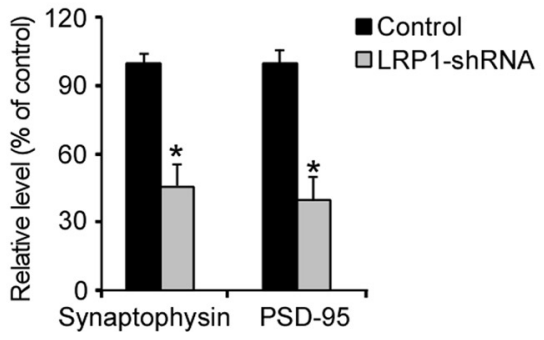

Figure 6. LRP1 knockdown in primary neurons results in neurite degeneration. $A$, Primary cortical neurons cultured from wild-type $C 57 B L / 6 \mathrm{~J}$ mice were infected by lentivirus carrying LRP1-shRNA on day 8 of in vitro culture. On day 4 and day 5 after infection, LRP1 expression was analyzed by Western blotting. $\boldsymbol{B}$, Densitometric quantification of LRP1 expression showed that LRP1 was effectively knocked down on day 5 after infection with lentiviral shRNA. C, Following infection of lentiviral LRP1-shRNA in primary neurons, conditioned media from astrocytes of wild-type (WT) control or apoE3 target replacement mice with equal amounts of apoE were added and incubated with neurons for $24 \mathrm{~h}$. Total cholesterol content in neurons under each condition was measured. D, Following infection of lentiviral LRP1-shRNA in primary neurons, conditional media from WT astrocytes was added to the neuronal culture media and immunofluorescence staining was assessed using a microtubule-associated protein (MAP)-2 antibody (detected by Alexa 488, green). Shown are images of representative staining. $\boldsymbol{E}$, Quantification of neurite length and numbers of MAP-2 staining neurons indicates that LRP1 knockdown significantly reduces the length and numbers of neurites in primary cultured neurons. $F$, Following infection of lentiviral LRP1-shRNA in primary neurons, expression of synaptophysin, PSD-95, and actin was analyzed by Western blotting. $\boldsymbol{G}$, Densitometric quantification of Western blots in $\boldsymbol{F}$ showed that the expression of synaptophysin and PSD-95 was significantly decreased in LRP1 knocked down neurons. The data represent the means \pm SD. ${ }^{*} p<0.05,{ }^{* *} p<0.01$.

ketone, under the conditions of inadequate glucose availability or increased energy demands (Prins, 2008). Although brain cannot directly use fatty acids as an energy source, they can be converted to ketone and used by the brain. The glycerol component of triglycerides can be converted into glucose, via gluconeogenesis, and used as an energy source (Cherrington et al., 1991). Although triglyceride is not abundant in the brain, it is tempting to speculate that triglyceride may be used as an alternative energy source under certain conditions.

Dendritic spines are tiny protrusions along dendrites, which are essential for excitatory synaptic transmission. A loss or alteration of spines has been described in $\mathrm{AD}$ patients and in $\mathrm{AD}$ mouse models (Knobloch and Mansuy, 2008). We also found significant decrease in dendritic spine density in the hippocampal and cortical regions of LRP1-KO mice at 18 months of age. Synaptic degeneration appears to be an early event in the pathogenesis of AD (Masliah et al., 2001; Scheff et al., 2007), and synaptic impairment is likely to be the major contributor to memory loss in AD (Shankar and Walsh, 2009). These dendritic spine degen- eration and synaptic losses in LRP1 knock-out mice are likely due to the impairment of lipid metabolism. We found that while lipid metabolism is impaired at 12 months of age in LRP1 forebrain knock-out mice, degeneration of dendritic spines and synapses occurs only at older ages (18 months). Changes in the metabolism of other LRP1 ligands may also contribute to these defects. For example, thrombospondins, secreted by astrocytes, promote CNS synaptogenesis in vitro and in vivo (Christopherson et al., 2005). Further, tissue plasminogen activator (tPA) plays an important role in the LTP and synaptic growth in the hippocampal mossy fiber pathway (Baranes et al., 1998). Since both thrombospondins and tPA are ligands of LRP1, potential changes in their metabolism may also contribute to synapse loss and behavioral deficits in LRP1 knock-out mice.

The most important feature of AD pathology is neurodegeneration. In most amyloid model mice, neuronal loss was reported only after the dramatic occurrence of amyloid plaques (Bredesen, 2009). In our LRP1 knock-out mouse model, we observed significant neurodegeneration in the hippocampus and cortex in the 
absence of amyloid pathology only at 24 months of age, but not at 18 months of age. These pathological events parallel the progressive synaptic loss and neurodegeneration found in human $\mathrm{AD}$ brains (Shankar and Walsh, 2009). The neuroinflammation observed in LRP1 forebrain knock-out mice further indicates that neuropathology in the aged brain can occur in parallel with spine/synaptic loss in the absence of amyloid pathology.

The NMDA and AMPA receptors play essential roles in LTP, which is widely considered a major cellular mechanism underlying learning and memory. LTP is impaired in plaquebearing $\mathrm{AD}$ transgenic mice and in the brain slices that were treated with $\mathrm{A} \beta$ peptides (Querfurth and LaFerla, 2010). Disruptions of ion currents in the postsynaptic glutamate receptor result in part from the loss of surface NMDA receptors (Snyder et al., 2005) or AMPA receptors (Hsieh et al., 2006). Interestingly, we found that LRP1 deletion selectively decreases the protein levels of NMDAR1 and GluR1 in the brain and in primary cultured neurons. The decreased levels of NMDAR1, but not GluR1, can be rescued by addition of cholesterol to cultured neurons, suggesting that both cholesterol-dependent and independent mechanisms could contribute to the reduced levels of these glutamate receptor subunits in LRP1-deficient neurons. Interestingly, a previous study has demonstrated that addition of cholesterol to cultured neurons strongly enhances the number and efficacy of synapses (Mauch et al., 2001). Conversely, depletion of cholesterol/sphingolipid leads to instability of surface AMPA receptors and gradual loss of synapses and dendritic spines (Hering et al., 2003). The exact relationship between the loss of dendritic spines/synapses and selective glutamate receptors in LRP1 forebrain knock-out mice requires further investigation.

Our current study defines a critical role for LRP1 at synapses in the adult brain. Interestingly, a previous report by Herz and colleagues (May et al., 2004) demonstrated an important role for LRP1 in synaptic transmission by regulating the function of NMDAR and PSD-95 at the postsynapses. In that study, LRP1 deletion in the SynI-Cre model was detectable much earlier and throughout the entire CNS. In contrast, with our current CaMKII-Cre model, LRP1 deletion started between 3 and 6 months of age and gradually peaked at $\sim 12$ months of age and was restricted to the forebrain regions. Unlike the Syn-Cre/LRP1 mutant mice, which mostly died prematurely between 6 and 9 months of age, the CaMKII-Cre/LRP1 mutant mice live to old age, which allows us to analyze the function of LRP1 in the adult brain in an age-dependent manner. SynI-Cre/LRP1 mutant mice develop severe behavioral and motor abnormalities including hyperactivity, dystonia and systemic

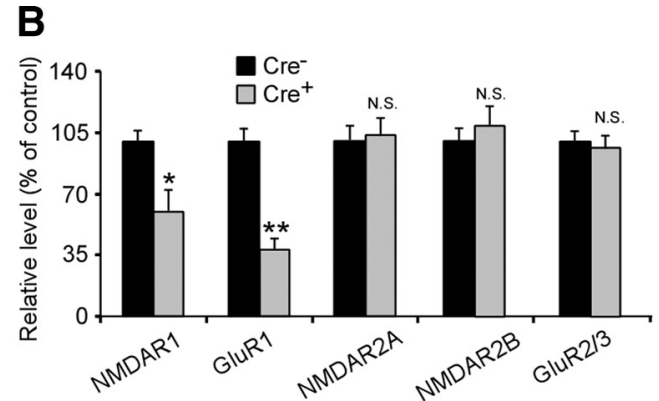

D

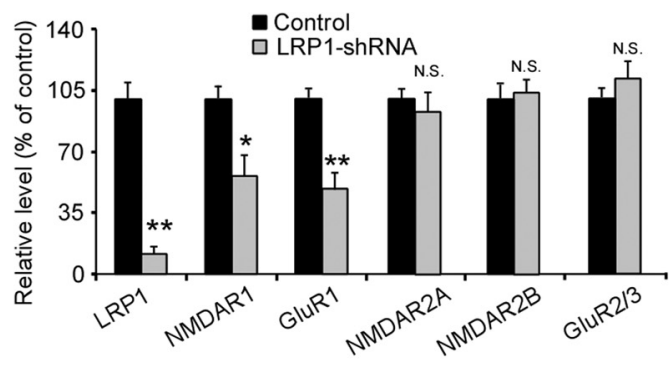

$\mathbf{F}$

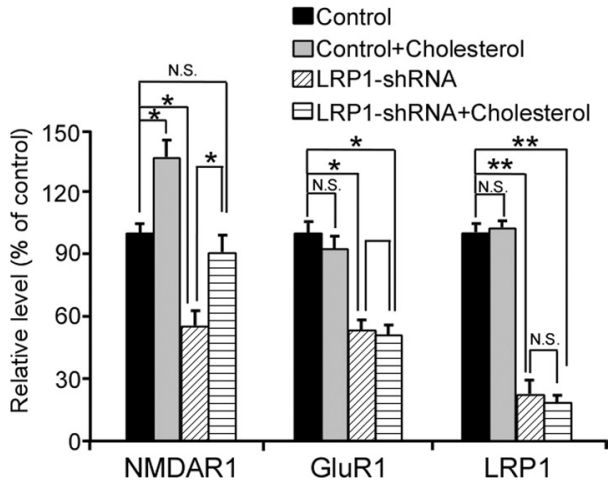

Figure 7. LRP1 deletion leads to decreased levels of NMDAR1 and GluR1. $A$, Expression of NMDAR1, NR2A, NR2B, GluR1, and GluR2/3 in the cortex were evaluated in 18 -month-old $\mathrm{Cre}^{+}$and $\mathrm{Cre}^{-}$mice by Western blotting. $\boldsymbol{B}$, Densitometric quantification of Western blots in $\boldsymbol{A}$ was performed as described in Experimental Procedures $(n=4)$. Note that expression of NMDAR1 and GluR 1 was significantly reduced in $\mathrm{Cre}^{+}$mice. C, Primary cortical neurons cultured from wild-type $557 \mathrm{BL} / 6 \mathrm{~J}$ mice were infected by carrying LRP1-shRNA on day 8 of in vitro culture. On day 5 after infection, expression of LRP1, actin, NMDAR1, NR2A 2B, GluR1, and GluR2/3 were analyzed by Western blotting. D, Densitometric quantification of Western blots in C showed that of NMDAR1 and GluR1 was significantly reduced in LRP1 knocked down neurons. $\boldsymbol{E}$, Following infection of lentivira LRP1, NMDAR1, and GluR1 showed that expression of NMDAR1, but not GluR1, was partially rescued by cholesterol in LRP1 knocked down neurons. The data represent the means \pm SD. ${ }^{*} p<0.05,{ }^{* *} p<0.01$.

tremors starting $\sim 3$ weeks after birth. This more severe and earlier phenotype emphasized a crucial role for LRP1 in motor circuitry and muscle control, but effectively precluded examining another critical role for LRP1 in the adult CNS (i.e., maintaining brain lipid homeostasis and associated age-dependent synaptic and neuronal integrity as we have described here).

In summary, this study uncovers a biological function for LRP1 in modulating brain lipid metabolism and the integrity of dendritic spines, synapses, and neuronal viability. These agedependent events strongly resemble the neuropathology seen in human $\mathrm{AD}$ brains. Our results also provide important insights into how apoE and apoE receptors participate in brain lipid metabolism, which is critical for maintaining the integrity and function of brain synapses. Since the $\varepsilon 4$ allele is the only genetic risk 
factor for late-onset $\mathrm{AD}$, future studies should explore how the apoE alleles (E2, E3, E4) differentially affect LRP1 function with age.

\section{References}

Baranes D, Lederfein D, Huang YY, Chen M, Bailey CH, Kandel ER (1998) Tissue plasminogen activator contributes to the late phase of LTP and to synaptic growth in the hippocampal mossy fiber pathway. Neuron 21:813-825.

Bosio A, Binczek E, Stoffel W (1996) Functional breakdown of the lipid bilayer of the myelin membrane in central and peripheral nervous system by disrupted galactocerebroside synthesis. Proc Natl Acad Sci U S A 93:13280-13285.

Bredesen DE (2009) Neurodegeneration in Alzheimer's disease: caspases and synaptic element interdependence. Mol Neurodegener 4:27.

Bu G (2009) Apolipoprotein E and its receptors in Alzheimer's disease: pathways, pathogenesis and therapy. Nat Rev Neurosci 10:333-344.

Bu G, Maksymovitch EA, Nerbonne JM, Schwartz AL (1994) Expression and function of the low density lipoprotein receptor-related protein (LRP) in mammalian central neurons. J Biol Chem 269:18521-18528.

Cam JA, Zerbinatti CV, Li Y, Bu G (2005) Rapid endocytosis of the low density lipoprotein receptor-related protein modulates cell surface distribution and processing of the beta-amyloid precursor protein. J Biol Chem 280:15464-15470.

Cheng H, Jiang X, Han X (2007) Alterations in lipid homeostasis of mouse dorsal root ganglia induced by apolipoprotein E deficiency: a shotgun lipidomics study. J Neurochem 101:57-76.

Cherrington AD, Frizzell RT, Biggers DW, Connolly CC (1991) Hypoglycemia, gluconeogenesis and the brain. Adv Exp Med Biol 291:197-211.

Christopherson KS, Ullian EM, Stokes CC, Mullowney CE, Hell JW, Agah A, Lawler J, Mosher DF, Bornstein P, Barres BA (2005) Thrombospondins are astrocyte-secreted proteins that promote CNS synaptogenesis. Cell 120:421-433.

Coetzee T, Fujita N, Dupree J, Shi R, Blight A, Suzuki K, Suzuki K, Popko B (1996) Myelination in the absence of galactocerebroside and sulfatide: normal structure with abnormal function and regional instability. Cell 86:209-219.

Deane R, Wu Z, Sagare A, Davis J, Du Yan S, Hamm K, Xu F, Parisi M, LaRue B, Hu HW, Spijkers P, Guo H, Song X, Lenting PJ, Van Nostrand WE, Zlokovic BV (2004) LRP/amyloid beta-peptide interaction mediates differential brain efflux of Abeta isoforms. Neuron 43:333-344.

Han X (2007) Potential mechanisms contributing to sulfatide depletion at the earliest clinically recognizable stages of Alzheimer's disease: a tale of shotgun lipidomics. J Neurochem 103:171-179.

Han X, Gross RW (2005) Shotgun lipidomics: Electrospray ionization mass spectrometric analysis and quantitation of the cellular lipidomes directly from crude extracts of biological samples. Mass Spectrom Rev 24:367-412.

Han X, M Holtzman D, McKeel DW Jr, Kelley J, Morris JC (2002) Substantial sulfatide deficiency and ceramide elevation in very early Alzheimer's disease: potential role in disease pathogenesis. J Neurochem 82:809-818.

Han X, Cheng H, Fryer JD, Fagan AM, Holtzman DM (2003) Novel role for apolipoprotein $\mathrm{E}$ in the central nervous system: modulation of sulfatide content. J Biol Chem 278:8043-8051.

Hering H, Lin CC, Sheng M (2003) Lipid rafts in the maintenance of synapses, dendritic spines, and surface AMPA receptor stability. J Neurosci 23:3262-3271.

Herz J, Bock HH (2002) Lipoprotein receptors in the nervous system. Annu Rev Biochem 71:405-434.

Herz J, Chen Y (2006) Reelin, lipoprotein receptors and synaptic plasticity. Nat Rev Neurosci 7:850-859.

Herz J, Clouthier DE, Hammer RE (1992) LDL receptor-related protein internalizes and degrades uPA-PAI-1 complexes and is essential for embryo implantation. Cell 71:411-421.

Hoe HS, Lee KJ, Carney RS, Lee J, Markova A, Lee JY, Howell BW, Hyman BT, Pak DT, Bu G, Rebeck GW (2009) Interaction of reelin with amyloid precursor protein promotes neurite outgrowth. J Neurosci 29:74597473.

Hsieh H, Boehm J, Sato C, Iwatsubo T, Tomita T, Sisodia S, Malinow R (2006) AMPAR removal underlies Abeta-induced synaptic depression and dendritic spine loss. Neuron 52:831-843.
Ishizuka I (1997) Chemistry and functional distribution of sulfoglycolipids Prog Lipid Res 36:245-319.

Jiang Y, de Bruin A, Caldas H, Fangusaro J, Hayes J, Conway EM, Robinson ML, Altura RA (2005) Essential role for survivin in early brain development. J Neurosci 25:6962-6970.

Kang DE, Pietrzik CU, Baum L, Chevallier N, Merriam DE, Kounnas MZ Wagner SL, Troncoso JC, Kawas CH, Katzman R, Koo EH (2000) Modulation of amyloid beta-protein clearance and Alzheimer's disease susceptibility by the LDL receptor-related protein pathway. J Clin Invest 106:1159-1166.

Knobloch M, Mansuy IM (2008) Dendritic spine loss and synaptic alterations in Alzheimer's disease. Mol Neurobiol 37:73-82.

Li Y, Marzolo MP, van Kerkhof P, Strous GJ, Bu G (2000) The YXXL motif, but not the two NPXY motifs, serves as the dominant endocytosis signal for low density lipoprotein receptor-related protein. J Biol Chem 275:17187-17194.

Lillis AP, Van Duyn LB, Murphy-Ullrich JE, Strickland DK (2008) LDL receptor-related protein 1: unique tissue-specific functions revealed by selective gene knockout studies. Physiol Rev 88:887-918.

Liu Q, Zerbinatti CV, Zhang J, Hoe HS, Wang B, Cole SL, Herz J, Muglia L, Bu $\mathrm{G}$ (2007) Amyloid precursor protein regulates brain apolipoprotein $\mathrm{E}$ and cholesterol metabolism through lipoprotein receptor LRP1. Neuron 56:66-78.

Mahley RW (1988) Apolipoprotein E: cholesterol transport protein with expanding role in cell biology. Science 240:622-630.

Masliah E, Mallory M, Alford M, DeTeresa R, Hansen LA, McKeel DW Jr, Morris JC (2001) Altered expression of synaptic proteins occurs early during progression of Alzheimer's disease. Neurology 56:127-129.

Mauch DH, Nägler K, Schumacher S, Göritz C, Müller EC, Otto A, Pfrieger FW (2001) CNS synaptogenesis promoted by glia-derived cholesterol. Science 294:1354-1357.

May P, Rohlmann A, Bock HH, Zurhove K, Marth JD, Schomburg ED, Noebels JL, Beffert U, Sweatt JD, Weeber EJ, Herz J (2004) Neuronal LRP1 functionally associates with postsynaptic proteins and is required for normal motor function in mice. Mol Cell Biol 24:8872-8883.

Merrill AH Jr, Schmelz EM, Dillehay DL, Spiegel S, Shayman JA, Schroeder JJ, Riley RT, Voss KA, Wang E (1997) Sphingolipids-the enigmatic lipid class: biochemistry, physiology, and pathophysiology. Toxicol Appl Pharmacol 142:208-225.

Moestrup SK, Gliemann J, Pallesen G (1992) Distribution of the alpha 2-macroglobulin receptor/low density lipoprotein receptor-related protein in human tissues. Cell Tissue Res 269:375-382.

Morikawa M, Fryer JD, Sullivan PM, Christopher EA, Wahrle SE, DeMattos RB, O’Dell MA, Fagan AM, Lashuel HA, Walz T, Asai K, Holtzman DM (2005) Production and characterization of astrocyte-derived human apolipoprotein $\mathrm{E}$ isoforms from immortalized astrocytes and their interactions with amyloid-beta. Neurobiol Dis 19:66-76.

Pfrieger FW (2003) Cholesterol homeostasis and function in neurons of the central nervous system. Cell Mol Life Sci 60:1158-1171.

Prins M (2008) Diet, Ketones, and neurotrauma. Epilepsia 49 [Suppl 8]:111113.

Puglielli L, Tanzi RE, Kovacs DM (2003) Alzheimer's disease: the cholesterol connection. Nat Neurosci 6:345-351.

Qiu S, Zhao LF, Korwek KM, Weeber EJ (2006) Differential reelin-induced enhancement of NMDA and AMPA receptor activity in the adult hippocampus. J Neurosci 26:12943-12955.

Querfurth HW, LaFerla FM (2010) Alzheimer's disease. N Engl J Med 362:329-344

Rohlmann A, Gotthardt M, Hammer RE, Herz J (1998) Inducible inactivation of hepatic LRP gene by cre-mediated recombination confirms role of LRP in clearance of chylomicron remnants. J Clin Invest 101:689-695.

Scheff SW, Price DA, Schmitt FA, DeKosky ST, Mufson EJ (2007) Synaptic alterations in CA1 in mild Alzheimer disease and mild cognitive impairment. Neurology 68:1501-1508.

Shankar GM, Walsh DM (2009) Alzheimer's disease: synaptic dysfunction and Abeta. Mol Neurodegener 4:48.

Snyder EM, Nong Y, Almeida CG, Paul S, Moran T, Choi EY, Nairn AC, Salter MW, Lombroso PJ, Gouras GK, Greengard P (2005) Regulation of NMDA receptor trafficking by amyloid-beta. Nat Neurosci 8:1051-1058.

Su KL, Sun GY (1978) Acyl group composition of metabolically active lipids in brain: variances among subcellular fractions and during postnatal development. J Neurochem 31:1043-1047. 
Tsien JZ, Chen DF, Gerber D, Tom C, Mercer EH, Anderson DJ, Mayford M, Kandel ER, Tonegawa S (1996) Subregion- and cell type-restricted gene knockout in mouse brain. Cell 87:1317-1326.

Valenza M, Rigamonti D, Goffredo D, Zuccato C, Fenu S, Jamot L, Strand A, Tarditi A, Woodman B, Racchi M, Mariotti C, Di Donato S, Corsini A, Bates G, Pruss R, Olson JM, Sipione S, Tartari M, Cattaneo E (2005) Dysfunction of the cholesterol biosynthetic pathway in Huntington's disease. J Neurosci 25:9932-9939.

van Kerkhof P, Lee J, McCormick L, Tetrault E, Lu W, Schoenfish M, Oorschot V, Strous GJ, Klumperman J, Bu G (2005) Sorting nexin 17 facilitates LRP recycling in the early endosome. EMBO J 24:2851- 2861.

Vance JE, Karten B, Hayashi H (2006) Lipid dynamics in neurons. Biochem Soc Trans 34:399-403.
Weeber EJ, Beffert U, Jones C, Christian JM, Forster E, Sweatt JD, Herz J (2002) Reelin and ApoE receptors cooperate to enhance hippocampal synaptic plasticity and learning. J Biol Chem 277:39944-39952.

West MJ, Slomianka L, Gundersen HJ (1991) Unbiased stereological estimation of the total number of neurons in thesubdivisions of the rat hippocampus using the optical fractionator. Anat Rec 231:482-497.

Yang K, Cheng H, Gross RW, Han X (2009) Automated lipid identification and quantification by multidimensional mass spectrometry-based shotgun lipidomics. Anal Chem 81:4356-4368.

Zerbinatti CV, Wahrle SE, Kim H, Cam JA, Bales K, Paul SM, Holtzman DM, Bu G (2006) Apolipoprotein E and low density lipoprotein receptorrelated protein facilitate intraneuronal Abeta 42 accumulation in amyloid model mice. J Biol Chem 281:36180-36186. 